\title{
COVID-19 during the crisis in the Syrian Arab Republic
}

\author{
Rahim Abo Kasem ${ }^{1}$ and Mohammad Almansour ${ }^{1}$ \\ Damascus University, Damascus, Syrian Arab Republic (Correspondence to: Rahim Abo Kasem: rahimabu99@gmail.com).
}

Citation: Abo Kasem R; Almansour M. COVID-19 during the crisis in the Syrian Arab Republic. East Mediterr Health J. 2021;27(1):5-6. https://doi. $\operatorname{org} / 10.26719 / 2021.27 .1 .5$

Received: 08/07/20; accepted: 29/09/20

Copyright (C) World Health Organization (WHO) 2021. Open Access. Some rights reserved. This work is available under the CC BY-NC-SA 3.0 IGO license (https://creativecommons.org/licenses/by-nc-sa/3.o/igo)

In December 2019, an unknown cause of pneumonia was announced in Wuhan, China (1). The pathogen was later identified as severe acute respiratory syndrome coronavirus 2 (SARS-CoV-2), and the disease was named coronavirus 2019 (COVID-19) by the World Health Organization (WHO). On 30 January 2020, the WHO announced (COVID-19) as a Public Health Emergency of International Concern (PHEIC). However, as a result of the rapid spread of the disease worldwide, COVID-19 outbreak was announced as a global pandemic on March 11 (2). Until 24 August 2020, about 23,311,719 laboratory-confirmed cases of COVID-19, including 806,410 deaths, have been reported globally (3).

The pandemic had severe health and economic impacts globally, which were even worse in low-income countries. For instance, Syria, which has suffered from a 9-year war, was classified as a high-risk area according to the global risk assessment by WHO even before reporting the first confirmed case (4). This high-risk estimation was due to, among other reasons, the large number of vulnerable people, the religious tourism, fragile health system, and limited resources (4).

As of March 2020, the Syrian authorities started to take strict measures at harbors, land- border crossing points and Damascus International Airport, including temperature measurement and checking travel history to detect any suspected cases of COVID-19, and finally traveling was banned unless for certain humanitarian or trade exemptions (5). Moreover, starting from 24 March 2020, a night curfew was imposed in addition to further measures like reducing the number of workers in the public institutions as well as suspension of universities, schools, and institutes (6).

The first case of COVID-19 in Syria was reported on 22 March 2020 for a traveler from another country (6), while the first confirmed death was reported on 29 March 2020 (7). However, COVID-19 cases started to increase significantly after 26 May 2020 when some precautionary measures were lifted, such as the curfew, the travel ban between and within governorates, and universities and institutions suspension (8). As of 20 August 2020, the Syrian Ministry of Health has confirmed (2008) cases of COVID-19, including (82) deaths and (460) recoveries (9). The majority of reported cases are in Damascus and Aleppo, followed by rural Damascus and Latakia. To notice, these official numbers were doubled within three weeks, which indicates that community transmission is widespread. Moreover, there is a concern that the actual number of cases is much higher than the reported ones due to poor testing capacity that results in many asymptomatic or mild cases to remain undiagnosed (9).

According to published data, 76 COVID-19 cases were among healthcare workers as of 20 August 2020, the majority of these cases are in Damascus. Moreover, it is estimated that one in five cases in north-east Syria is of healthcare worker. An estimation that raises the urgent need for providing more personal protective equipments (PPE) for healthcare workers (9).

Several factors were hypothesized to explain the relatively low-reported number of COVID-19 cases in Syria especially between March and May 2020 (10); In our opinion, firstly, the few numbers of tests being conducted due to the low numbers of diagnostics kits and equipped laboratories. Secondly, the lack of transportation movement between Syria and the rest of the world. Finally, the precautionary measures that were taken early in March. However, the situation was significantly deteriorated later which might indicate the lack of preventive measures at the individual and community level, as well as the impact of the undetected cases on the subsequent prevalence.

The nine years of conflict In Syria caused a deterioration of Syria's health system, by the end of December 2019, and out of 113 public hospitals assessed by WHO, only $50 \%$ (57) were fully functioning and $43 \%(49)$ were damaged. Syrian hospitals are still suffering from a shortage and/or malfunction of medical devices and equipment, and there is a shortage of beds at varying degrees across all governorates (11). An estimated capacity to manage a maximum number of 6,500 patients all over the country is reported. This capacity varies widely across Syria (12), and the medical devices are overburdened by increased numbers of people in safe areas (11).

Several factors make the epidemiological situation more critical In Syria; around $80 \%$ of the population live in poverty, thus home quarantine measures could have severe consequences for the population (12). Social And economical impacts of COVID-19 are likely to exacerbate existing substantial humanitarian needs across the country (13). In addition, internationally recommended measures are unlikely to be enforceable or effective in areas where overcrowding 
are rife (12), especially in Damascus/Rural Damascus, Aleppo and Homs (13), as well as other areas including Deir-Ez-Zor, where conflict may be ongoing making sample collection more challenging (13). SARS-CoV-2 could spread rapidly through affected populations, particularly among those in the most vulnerable groups (12).

More challenges face the Syrian health system, for example, the poor surveillance system and lack of a standardized method for reporting infections (14). Moreover, numbers of qualified healthcare workers at the frontline of healthcare provision are insufficient and in continuous threat due to lack of PPE. Thus, they are particularly vulnerable not only to the risk of infection but also to ethical challenges posed by the current situation, including difficult triage and resource allocation decisions $(12,13)$.

In conclusion, we think that there is a crucial need for a comprehensive and evidence-based health plan in Syria in coordination with nongovernmental organizations and community bodies to improve detecting, monitoring, and tracking of cases in order to improve hospitals' capacities, and to manage received aids fairly and prudently.

\section{Acknowledgement}

We would like to thank Dr. Lugien Alasadi and Hala Haidar, who helped us in proofreading.

Funding: None.

Competing interests: None declared.

\section{References}

1. Huang C, Wang Y, Li X, Ren L, Zhao J, Hu Y, et al. Clinical features of patients infected with 2019 novel coronavirus in Wuhan, China. Lancet (London, England) 2020;395:497-506. doi: 10.1016/So140-6736(20)30183-5.

2. WHO Western Pacific | World Health Organization. https://www.who.int/westernpacific/emergencies/covid-19.

3. WHO Coronavirus Disease (COVID-19) Dashboard I WHO Coronavirus Disease (COVID-19) Dashboard [Internet]. [cited 2020 Aug 25]. Available from: https://covid19.who.int/?fbclid=IwARokeQgEtyHfUYvgVqiPVcSyfoD402oKtoYlWgAlYkURgKoSFoBoo6DmWZU

4. Syrian Arab Republic: COVID-19 Update No. 02 - 11 March 2020 - Syrian Arab Republic [Internet]. ReliefWeb. [cited 2020 Aug 28]. Available from: https://reliefweb.int/report/syrian-arab-republic/syrian-arab-republic-covid-19-update-no-02-11-march-2020

5. Syrian Arab Republic: COVID-19 Update No. 01 - 2 March 2020 - Syrian Arab Republic [Internet]. ReliefWeb. [cited 2020 Aug 25 ]. Available from: https://reliefweb.int/report/syrian-arab-republic/syrian-arab-republic-covid-19-update-no-01-2-march-2020

6. Syrian Arab Republic: COVID-19 Update No. 03 - 25 March 2020 - Syrian Arab Republic | ReliefWeb [Internet]. [cited 2020 Aug 25]. Available from: https://reliefweb.int/report/syrian-arab-republic/syrian-arab-republic-covid-19-update-no-03-25-march-2020?fbclid=IwAR3YrN5_q-Noku9HCkduGiPIMMs6ClLaENzryjkL-3YQPVzrL_L2oMwldGA

7. Syrian Arab Republic: COVID-19 Update No. 05 - 10 April 2020 - Syrian Arab Republic [Internet]. ReliefWeb. [cited 2020 Aug 28]. Available from: https://reliefweb.int/report/syrian-arab-republic/syrian-arab-republic-covid-19-update-no-05-10-april-2020

8. Syrian Arab Republic: COVID-19 Response Update No. 05 - 5 June 2020 - Syrian Arab Republic [Internet]. ReliefWeb. [cited 2020 Aug 25]. Available from: https://reliefweb.int/report/syrian-arab-republic/syrian-arab-republic-covid-19-response-update-no-05-5june-2020

9. Syrian Arab Republic: COVID-19 Response Update No. 09 - 21 August 2020 - Syrian Arab Republic [Internet]. ReliefWeb. [cited 2020 Aug 25]. Available from: https://reliefweb.int/report/syrian-arab-republic/syrian-arab-republic-covid-19-response-update-no09-21-august-2020

10. Syrian Arab Republic: COVID-19 Update No. 16 - 16 August 2020 - Syrian Arab Republic [Internet]. ReliefWeb. [cited 2020 Aug 25]. Available from: https://reliefweb.int/report/syrian-arab-republic/syrian-arab-republic-covid-19-update-no-16-16-august-2020

11. Mediterranean WHORO for the E. HeRAMS annual report January - December 2019 public hospitals in the Syrian Arab Republic. 2020 Jul [cited 2020 Aug 6]; Available from: https://apps.who.int/iris/handle/10665/3331847

12. Abbara A, Rayes D, Fahham O, Alhiraki OA, Khalil M, Alomar A, et al. Coronavirus 2019 and health systems affected by protracted conflict: The case of Syria. International Journal of Infectious Diseases. 2020 Jul 1;96:192-5.

13. Syrian Arab Republic: COVID-19 Update No. 15 - 24 July 2020 - Syrian Arab Republic [Internet]. ReliefWeb. [cited 2020 Aug 6]. Available from: https://reliefweb.int/report/syrian-arab-republic/syrian-arab-republic-covid-19-update-no-15-24-july-2020

14. EU guidance impedes humanitarian action to prevent COVID-19 in Syria [Internet]. [cited 2020 Aug 6]. Available from: https:// www.ncbi.nlm.nih.gov/pmc/articles/PMC7332264/?fbclid=IwARo8q3bafvCewRKnCOcaSPT1UYScGrHDbcdZJyiDxf_MCNpUaliP3KTjJBo 